\title{
Production of xylooligosaccharides by autohydrolysis of hazelnut (Corylus avellana L.) shell
}

\author{
Ece Surek, Ali Oguz Buyukkileci* \\ Department of Food Engineering, Faculty of Engineering, Izmir Institute of Technology, 35430 Gulbahce, Urla, Izmir, Turkey
}

\section{A R T I C L E I N F O}

\section{Article history:}

Received 24 March 2017

Received in revised form 30 May 2017

Accepted 27 June 2017

Available online 29 June 2017

Chemical compounds studied in this article:

D-Glucose (PubChem CID: 5793)

D-Galactose (PubChem CID: 6036)

D-Arabinose (PubChem CID: 66308)

D-Xylose (PubChem CID: 135191)

Xylobiose (PubChem CID: 439538)

Xylotriose (PubChem CID: 10201852)

Xylotetraose (PubChem CID: 10230811)

Xylopentaose (PubChem CID: 10146542)

Xylohexaose (PubChem CID: 74539951)

Keywords:

Hazelnut residues

Hazelnut shell

Xylooligosaccharide

Autohydrolysis

Severity factor

\begin{abstract}
A B S T R A C T
Hazelnut shell (HS), husk and pruning residues were characterized and evaluated for xylooligosaccharides (XOS) production by autohydrolysis. HS contained the highest amount of xylan and yielded more XOS compared to other hazelnut residues. The temperature and holding time of HS autohydrolysis greatly influenced the composition of the liquor and the remaining solid. The highest XOS yield $(62 \%$ of the feedstock xylan) was obtained at $190^{\circ} \mathrm{C}$ and $5 \mathrm{~min}$ of holding time. At this temperature, $30 \mathrm{~min}$ of holding time was required to maximize the percentage of XOS with low degree of polymerization. Xylose, acetic acid and furfural concentrations increased with treatment severity. The concentrations of the products in the autohydrolysis liquors followed specific trends with changing severity factor $\left(\log R_{o}\right)$ values. Solubilization of xylan in the treatments enhanced the cellulose and lignin contents in the remaining solids.
\end{abstract}

(C) 2017 Elsevier Ltd. All rights reserved.

\section{Introduction}

Hazelnut (Corylus avellana L.) is one of the important agricultural products in Turkey. In 2009-2014 period, average annual hazelnut (with shells) production was 0.53 million tons, corresponding to $65 \%$ of the world total output (FAOSTAT, 2017). Husks, hard shells, and pruning residues are discarded during harvesting and processing of hazelnuts. Hazelnut husk is the green leafy cover around the hard shell and it is removed mechanically after the harvest (Shahidi, Alasalvar, \& Liyana-Pathirana, 2007). The brown hard shell holding the edible kernel is removed using mechanical crackers. The pruning residues are the woody biomass generated during two pruning operations each year. According to 2003 data, the amounts of residual shells and prunings were 0.45 and 1.7 million tons, respectively, as a result of hazelnut production of 0.65 million tons

\footnotetext{
* Corresponding author.

E-mail addresses: ecesurek@iyte.edu.tr (E. Surek), oguzbuyukkileci@iyte.edu.tr (A.O. Buyukkileci).
}

(Alkaya, Altay, Ata, Çakar, \& Durtas, 2010). The amount of husk discarded annually was estimated as 0.20 million tons (Guney, 2013). These residues are generally used in house heating or burned in fields (Çöpür, Tozluoglu, \& Özkan, 2013; Guney, 2013). Previous attempts towards valorization of hazelnut residues include production of ethanol (Çöpür et al., 2013) and particle board (Çöpür, Güler, Akgül, \& Taşçioğlu, 2007) from husks, and antioxidant phytochemicals recovery from skin, green leafy cover, tree leaf and shells (Shahidi et al., 2007; Xu et al., 2012). In a recent study, the methanol extract of hazelnut shells exhibited inhibitory effect on the growth of human cancer cell lines, as well as anti-oxidant activity (Esposito et al., 2017).

Hazelnut residues are lignocellulosic biomass, which can be fractionated into cellulose, hemicellulose and lignin, and processed into valuable bio-based chemicals and materials. The hemicellulosic part is composed mainly of xylan, which has potential as a feedstock for production of XOS having prebiotic activity. Currently, inulin and fructooligosaccharides (FOS) are dominating the prebiotics market, while XOS are considered as emerging prebiotics (Otieno \& Ahring, 2012). XOS are produced from agricultural 
and agro-industrial residues, which are abundant, inexpensive, and renewable biomass feedstocks. XOS have been shown to have better properties than FOS in terms of stability and heat resistance at low pH (Otieno \& Ahring, 2012) and they were required at lower doses than FOS and galactooligosaccharides (GaOS) for prebiotic activity (Finegold et al., 2014). In the human body, XOS are not digested or absorbed in the gastrointestinal tract and reaches colon, where they selectively stimulate the growth of beneficial bacteria, such as Bifidobacterium and Lactobacillus species and enhance short chain fatty acid production (Samanta et al., 2015; Singh et al., 2015). Among the health benefits of this prebiotic activity are; prevention of the growth of pathogenic bacteria, improvement of mineral absorption and bowel functions, protection against cardiovascular disease, reduction of the risk of colon cancer, and exhibiting immunostimulatory activity (Aachary \& Prapulla, 2011; Carvalho et al., 2013).

XOS are produced from xylan containing lignocellulosic biomass by direct enzymatic hydrolysis, chemical extraction followed by enzymatic hydrolysis, and hydrolysis of xylan by hydrothermal treatments using water, steam or acid catalysts under pressure (Parajó, Garrote, Cruz, \& Dominguez, 2004). The production of XOS with steam or acid may produce a large amount of monosaccharides and dehydration products (Aachary \& Prapulla, 2011). Direct enzymatic hydrolysis of xylan in the lignocellulosic network can only be applied to non-recalcitrant biomass, such as fruit peels (Parajó et al., 2004; Samanta et al., 2015). Autohydrolysis, in which biomass is treated with only water at elevated temperatures, leads hydrolytic depolymerization of xylan backbone and production of XOS (Parajó et al., 2004; Samanta et al., 2015). In autohydrolysis, autoionization of water and removal of acetyl groups on xylan as acetic acid increase the acidity of the reaction medium (Aachary \& Prapulla, 2011; Otieno \& Ahring, 2012). Hydronium ions and acetic acid catalyze the removal of xylan from the lignocellulosic network and the degradation of it into high or low molecular weight XOS and xylose (Aachary \& Prapulla, 2011).

Autohydrolysis has been applied to obtain XOS from various lignocellulosic biomass, such as olive pruning wastes (Cara et al., 2012), brewery's spent grain (Carvalheiro, Esteves, Parajó, Pereira, \& Gírio, 2004), almond shells, olive stones (Nabarlatz, Ebringerová, \& Montané, 2007), wheat straws (Carvalheiro, Silva-Fernandes, Duarte, \& Gírio, 2009), sunflower stalk (Akpinar, Gunay, Yilmaz, Levent, \& Bostanci, 2010), and Eucalyptus wood, rice husks and barley husks and corncobs (Nabarlatz et al., 2007; Parajó et al., 2004). Due to the differences in the structure of the feedstocks and the conditions of the production process, the composition and the structure of the XOS obtained can be different (Nabarlatz et al., 2007). Molecular weight of the XOS is low when the conditions are severe; however, that also enhances the formation of xylose and other monosaccharides. Furfural, hydroxymethylfurfural (HMF), acetic, formic and some other acids are also produced as a result of degradation of carbohydrates (Aachary \& Prapulla, 2011).

The aim of this study was to determine the potential of hazelnut residues as a feedstock for XOS production by autohydrolysis. The effects of autohydrolysis temperature and holding time on XOS yield from xylan, by-product formation and the distribution of molecular weight of the XOS were investigated. Severity factor was used to evaluate the combined effect of temperature and holding time on the reaction products.

\section{Materials and methods}

\subsection{Raw materials}

Hazelnut shell (HS), husk and pruning residues were collected from Ordu region, Turkey. The residues were dried in an oven
Table 1

Composition of hazelnut residues. ${ }^{a}$

\begin{tabular}{llll}
\hline \multirow{2}{*}{ components } & \multicolumn{2}{l}{ content $(\mathrm{g} / 100 \mathrm{~g}$ dry material $)$} \\
\cline { 2 - 4 } & shell & husk & pruning residues \\
\hline cellulose & $18.7 \pm 0.5$ & $15.4 \pm 1.5$ & $34.7 \pm 4.3$ \\
Klason lignin & $46.4 \pm 0.2$ & $25.9 \pm 0.7$ & $25.4 \pm 0.8$ \\
acid soluble lignin & $0.3 \pm 0.0$ & $0.3 \pm 0.0$ & $0.4 \pm 0.0$ \\
xylan & $18.7 \pm 0.1$ & $5.8 \pm 0.2$ & $12.8 \pm 1.6$ \\
galactan & $1.6 \pm 0.3$ & $2.6 \pm 0.1$ & $1.3 \pm 0.5$ \\
arabinan & $0.3 \pm 0.0$ & $1.7 \pm 0.2$ & $1.0 \pm 0.0$ \\
acetyl groups & $2.6 \pm 0.3$ & $1.2 \pm 0.1$ & $2.0 \pm 0.1$ \\
acetyl/xylose & 0.4 & 0.5 & 0.5 \\
uronic acids & $5.3 \pm 1.7$ & $10.6 \pm 2.4$ & $9.4 \pm 1.1$ \\
ash & $0.9 \pm 0.1$ & $5.0 \pm 0.3$ & $1.0 \pm 0.0$ \\
protein & $2.8 \pm 0.1$ & $8.0 \pm 0.2$ & $4.5 \pm 0.1$ \\
extractives & $1.2 \pm 0.3$ & $24.6 \pm 1.7$ & $4.0 \pm 0.3$ \\
total & 102.3 & 103 & 98.6 \\
\hline
\end{tabular}

a values are means of triplicate measurements \pm standard deviations.

b expressed as molar ratio.

at $60^{\circ} \mathrm{C}$ for $24 \mathrm{~h}$ and then milled to a particle size of less than $2 \mathrm{~mm}$. All chemicals were of analytical grade and purchased from Sigma-Aldrich (Steinheim, Germany) and Merck Millipore (Darmstadt, Germany). The XOS standards were obtained from Megazyme (Bray, Ireland).

\subsection{Autohydrolysis}

The autohydrolysis treatments were carried out in duplicates in a high pressure reactor (BR-300, Berghof, Eningen, Germany). The stainless steel tank (height: $18 \mathrm{~cm}$, diameter: $7 \mathrm{~cm}$ ) with $600 \mathrm{~mL}$ working volume was heated by the surrounding heating block. The content was continuously stirred by the paddle agitator rotating at $300 \mathrm{rpm}$. The biomass $(35 \mathrm{~g}$ ) was mixed with deionized water $(350 \mathrm{~mL})$ and the mixture was heated to selected temperature. The time required to reach $150^{\circ} \mathrm{C}, 160^{\circ} \mathrm{C}, 170^{\circ} \mathrm{C}, 180^{\circ} \mathrm{C}, 190^{\circ} \mathrm{C}$ and $200^{\circ} \mathrm{C}$ was $20 \mathrm{~min}, 26 \mathrm{~min}, 29 \mathrm{~min}, 36 \mathrm{~min}, 45 \mathrm{~min}$ and $46 \mathrm{~min}$, respectively. At the end of the reaction time, the reactor was rapidly cooled to $60^{\circ} \mathrm{C}$ in $20-25$ min with tap water circulating in the cooling coil. The liquid and solid phases were separated by filtration under vacuum. The residual solids were washed, dried at $45^{\circ} \mathrm{C}$ overnight and kept at room temperature until analysis. The filtrates (autohydrolysis liquors) were kept at $-20^{\circ} \mathrm{C}$.

Autohydrolysis was applied to HS, husk and pruning residues at $190^{\circ} \mathrm{C}$ for $15 \mathrm{~min}$ (excluding heating and cooling periods). The effect of autohydrolysis conditions on formation of XOS and reaction by-products from HS were investigated at selected temperatures $\left(150-200^{\circ} \mathrm{C}\right)$ and holding times $(0-45 \mathrm{~min})$.

In order to evaluate the combined effect of temperature $(\mathrm{T})$ and time $(\mathrm{t})$ on thermal treatment efficiency in a single variable, $\log$ arithmic values of severity factor $\left(\log R_{0}\right)$ were calculated for autohydrolysis treatments as expressed in Eq. (1) (Overend, Chornet, \& Gascoigne, 1987).

$R_{o}=\int_{0}^{t} \exp \left[\frac{\mathrm{T}-100}{14.75}\right] \mathrm{dt}$

where 14.75 is an empirical value related to activation energy of the reaction and 100 is the reference temperature $\left({ }^{\circ} \mathrm{C}\right)$. The reactor temperature profile during heating, retention and cooling was included in the $\log R_{o}$ calculation.

\subsection{Analytical methods}

\subsubsection{Compositional analysis of raw materials and processed solids}

The moisture content was determined by drying the biomass at $105^{\circ} \mathrm{C}$. The total protein content was determined by the Kjeldahl 
Table 2

Composition of processed solids from autohydrolysis of hazelnut residues. ${ }^{\text {a }}$

\begin{tabular}{|c|c|c|c|c|c|c|c|c|c|c|}
\hline \multirow[b]{2}{*}{ biomass } & \multicolumn{3}{|c|}{ treatment conditions } & \multirow[b]{2}{*}{$\begin{array}{l}\text { residual solids ( } \mathrm{g} / 100 \mathrm{~g} \\
\text { dry raw material) }\end{array}$} & \multicolumn{6}{|c|}{ component (g/100 g dry processed solid) } \\
\hline & temperature $\left({ }^{\circ} \mathrm{C}\right)$ & time (min) & $\log R_{0}$ & & cellulose & Klason lignin & xylan & galactan & acetyl groups & ash \\
\hline husk & 190 & 15 & 4.02 & $60.9 \pm 2.7$ & $31.1 \pm 1.4$ & $53.1 \pm 0.5$ & $5.7 \pm 0.1$ & $2.7 \pm 0.1$ & $0.40 \pm 0.05$ & $2.8 \pm 0.0$ \\
\hline pruning & 190 & 15 & 4.02 & $64.3 \pm 2.8$ & $57.7 \pm 2.3$ & $39.6 \pm 1.2$ & $5.3 \pm 0.1$ & $0.7 \pm 0.2$ & $0.79 \pm 0.05$ & $0.9 \pm 0.3$ \\
\hline shell & 150 & 15 & 2.73 & $87.7 \pm 0.7$ & $24.2 \pm 0.9$ & $46.8 \pm 0.1$ & $21.6 \pm 0.5$ & $0.8 \pm 0.1$ & $4.23 \pm 0.38$ & $0.8 \pm 0.0$ \\
\hline shell & 160 & 15 & 3.09 & $87.5 \pm 1.6$ & $22.5 \pm 1.4$ & $52.1 \pm 0.3$ & $14.6 \pm 2.6$ & $0.6 \pm 0.1$ & $3.57 \pm 0.35$ & $0.8 \pm 0.0$ \\
\hline shell & 170 & 15 & 3.36 & $77.4 \pm 0.1$ & $25.0 \pm 0.6$ & $50.8 \pm 2.6$ & $15.6 \pm 1.1$ & $0.6 \pm 0.0$ & $2.58 \pm 0.20$ & $0.7 \pm 0.0$ \\
\hline shell & 180 & 5 & 3.53 & $71.4 \pm 0.7$ & $26.8 \pm 1.4$ & $55.4 \pm 1.3$ & $12.2 \pm 0.7$ & $0.3 \pm 0.0$ & $2.14 \pm 0.18$ & $0.7 \pm 0.0$ \\
\hline shell & 180 & 15 & 3.63 & $70.5 \pm 0.5$ & $27.2 \pm 1.1$ & $54.9 \pm 1.5$ & $11.2 \pm 0.7$ & $0.4 \pm 0.1$ & $1.64 \pm 0.37$ & $0.6 \pm 0.0$ \\
\hline shell & 180 & 30 & 3.91 & $68.1 \pm 2.6$ & $27.8 \pm 0.9$ & $58.7 \pm 0.3$ & $4.5 \pm 0.5$ & $0.3 \pm 0.0$ & $0.95 \pm 0.01$ & $0.7 \pm 0.0$ \\
\hline shell & 180 & 45 & 4.03 & $68.2 \pm 1.8$ & $28.4 \pm 1.3$ & $62.7 \pm 2.8$ & $5.4 \pm 0.2$ & $0.2 \pm 0.0$ & $0.90 \pm 0.11$ & $0.6 \pm 0.0$ \\
\hline shell & 190 & 0 & 3.64 & $70.3 \pm 1.4$ & $22.4 \pm 2.5$ & $61.3 \pm 1.7$ & $10.3 \pm 3.0$ & $0.3 \pm 0.0$ & $1.09 \pm 0.14$ & $0.5 \pm 0.0$ \\
\hline shell & 190 & 5 & 3.92 & $66.5 \pm 1.3$ & $27.9 \pm 2.3$ & $58.7 \pm 0.9$ & $9.2 \pm 0.2$ & $0.2 \pm 0.0$ & $1.21 \pm 0.09$ & $0.6 \pm 0.0$ \\
\hline shell & 190 & 15 & 4.02 & $64.7 \pm 0.2$ & $29.3 \pm 0.2$ & $61.4 \pm 0.6$ & $6.5 \pm 0.5$ & $0.1 \pm 0.0$ & $0.66 \pm 0.25$ & $0.6 \pm 0.0$ \\
\hline shell & 190 & 30 & 4.15 & $64.6 \pm 0.3$ & $30.4 \pm 1.1$ & $63.1 \pm 1.5$ & $2.2 \pm 0.2$ & $0.2 \pm 0.0$ & $0.57 \pm 0.02$ & $0.7 \pm 0.1$ \\
\hline shell & 200 & 0 & 3.93 & $65.6 \pm 1.3$ & $30.4 \pm 0.4$ & $59.4 \pm 0.7$ & $5.9 \pm 0.9$ & $0.0 \pm 0.0$ & $0.84 \pm 0.14$ & $0.7 \pm 0.0$ \\
\hline shell & 200 & 15 & 4.29 & $61.8 \pm 0.6$ & $28.3 \pm 1.3$ & $67.9 \pm 0.6$ & $1.7 \pm 0.1$ & $0.1 \pm 0.0$ & $0.55 \pm 0.08$ & $0.6 \pm 0.0$ \\
\hline
\end{tabular}

${ }^{a}$ values are mean of duplicate autohydrolysis treatments \pm standard deviations.

method (protein $=6.25 \mathrm{xN}$ ). Total extractives content was calculated after treating the biomass sequentially with ultra-pure water and ethanol (96\%) in a Soxhlet apparatus. Ash content was measured by igniting the biomass in a muffle furnace according to ASTM E 1755-01. Uronic acid was determined spectrophotometrically using m-hydroxydiphenyl method (Melton \& Smith, 2001).

Carbohydrates, acid soluble and insoluble lignin contents were determined according to NREL/TP-510-42618. Extractive-free sample $(0.3 \mathrm{~g})$ was treated with $3 \mathrm{~mL}$ of $72 \%(\mathrm{w} / \mathrm{w}) \mathrm{H}_{2} \mathrm{SO}_{4}$ at room temperature for $60 \mathrm{~min}$ and diluted into $4 \%(\mathrm{w} / \mathrm{w})$ by deionized water. After keeping the suspension at $121^{\circ} \mathrm{C}$ for $1 \mathrm{~h}$ in an autoclave, the solid part was filtered through porcelain filter crucibles under vacuum and dried at $105^{\circ} \mathrm{C}$. The weight of this solid is reported as Klason lignin after subtracting the ash content. Acid soluble lignin was determined spectrophotometrically at $240 \mathrm{~nm}$ using an absorptivity value of $25 \mathrm{~L} / \mathrm{g} \mathrm{cm} . \mathrm{CaCO}_{3}$ was added to the filtrates to increase the $\mathrm{pH}$ to 5-7 and analyzed for glucose, xylose, galactose and arabinose in HPLC (Perkin Elmer, Waltham, MA) using a Rezex RPM-Monosaccharide column (Phenomenex, Torrance, CA) at $80^{\circ} \mathrm{C}$ and a refractive index (RI) detector. Ultra-pure water at a flow rate of $0.6 \mathrm{~mL} / \mathrm{min}$ was used as the mobile phase. Acetic acid concentration was measured similarly, except that samples were run on Aminex HPX-87H (Bio-Rad, Hercules, CA) column at $65^{\circ} \mathrm{C}$, using $5 \mathrm{mM} \mathrm{H}_{2} \mathrm{SO}_{4}$ as the mobile phase. Cellulose, xylan, galactan, arabinan contents were calculated by multiplying the glucose, xylose, galactose and arabinose concentrations, respectively, by anhydro correction factors ( 0.90 for hexoses and 0.88 for pentoses), and acetyl content was calculated by multiplying acetic acid concentration by 0.717 . The stability of glucose, xylose, galactose and arabinose in $4 \%$ acid hydrolysis was tested using standard solutions and recovery was measured to be above $95 \%$ for all monosaccharides.

The compositional analyses of processed solids after treatments were performed using the same methods applied to raw materials.

\subsubsection{Compositional analysis of autohydrolysis liquors}

Monomeric sugar and acetic acid concentrations were detected as described above. Formic acid was analyzed using the same HPLC conditions applied for acetic acid determination. The liquors were analyzed for furfural and HMF in HPLC (Agilent Technologies, Santa Clara, CA) coupled with diode-array detection (DAD) at $285 \mathrm{~nm}$ and $210 \mathrm{~nm}$, respectively, using Aminex HPX-87H column, as described above.

Total oligosaccharide contents of the autohydrolysis liquors were determined indirectly after quantitative acid hydrolysis with
$4 \% \mathrm{H}_{2} \mathrm{SO}_{4}$ at $121^{\circ} \mathrm{C}$ for $1 \mathrm{~h}$, according to NREL/TP-510-42623. The increase in the monomeric sugar concentrations in the liquors was expressed as the corresponding oligosaccharide content after multiplying by the anhydro correction factor. Similarly, acetyl groups bound to XOS were quantified by the difference of the acetic acid concentrations before and after the acid hydrolysis.

The XOS with degree of polymerization (DP) 2-6 in the liquors were measured by HPLC-RI (Perkin Elmer, Waltham, MA) using an Aminex HPX-42A column (Bio-Rad, Hercules, CA) at $80^{\circ} \mathrm{C}$ and water as the mobile phase at a flow rate of $0.6 \mathrm{~mL} / \mathrm{min}$. Resolution of the oligomers was improved by treating the samples with $\mathrm{NaOH}(10 \mathrm{~g} / \mathrm{L})$ for $15 \mathrm{~min}$. The samples were neutralized and filtered before HPLC analyses.

\section{Results and discussion}

\subsection{Composition of hazelnut residues}

The chemical composition of the residues was determined in order to select the relevant raw material(s) for XOS production. Furthermore, treatment efficiencies were evaluated by comparing the compositions of the streams after the treatments to those of the raw materials. Major components in the residues were lignin and cellulose followed by xylan, except hazelnut husk (HH), which was also rich in alcohol and water soluble materials (extractives) (Table 1). The ash and protein contents of the $\mathrm{HH}$ were also higher compared to those of the HS and the hazelnut pruning residues (HPR). Cellulose content of the HPR was considerably high.

Xylan contents of the hazelnut residues were of special interest to this study, since XOS are obtained by hydrolysis of this hemicellulosic polysaccharide. The HS contained the highest xylan (18.7\%) (Table 1). The other hemicellulosic carbohydrates in HS were galactan and arabinan, contents of which were markedly low compared to xylan. HS xylan was highly acetylated, which is typical for hardwood xylans. Uronic acid content of the HS was also high. The HPR hemicellulose had similar characteristics with a xylan content of $12.8 \%$. The HH contained comparably low amount of xylan (5.8\%), and the ratios of arabinan and galactan to xylan was higher than those in HS and HPR.

Cellulose and hemicellulose contents of HS used in the study were lower than reported in previous studies, while lignin content was in a good agreement (Aydinli \& Caglar, 2012; Çepelioğullar \& Pütün, 2014; Demirbas, 2008). Çöpür et al. (2013) observed higher carbohydrate, and lignin values for $\mathrm{HH}$ compared to this study. Differences may have been due to using different sources for feed- 

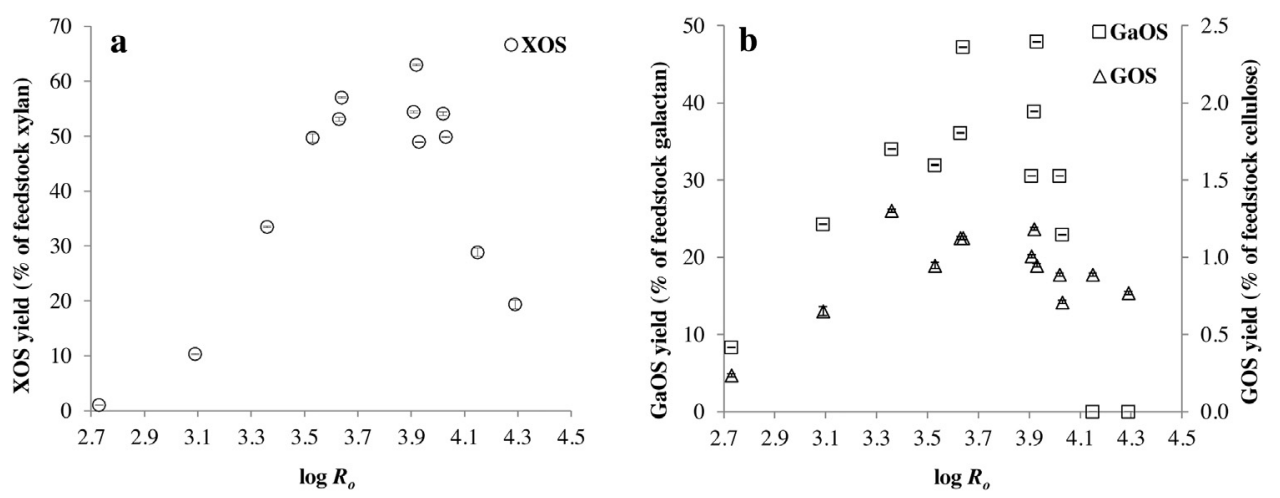

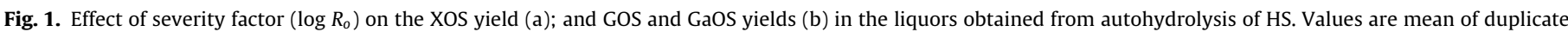
autohydrolysis treatments. Error bars represent standard deviation.

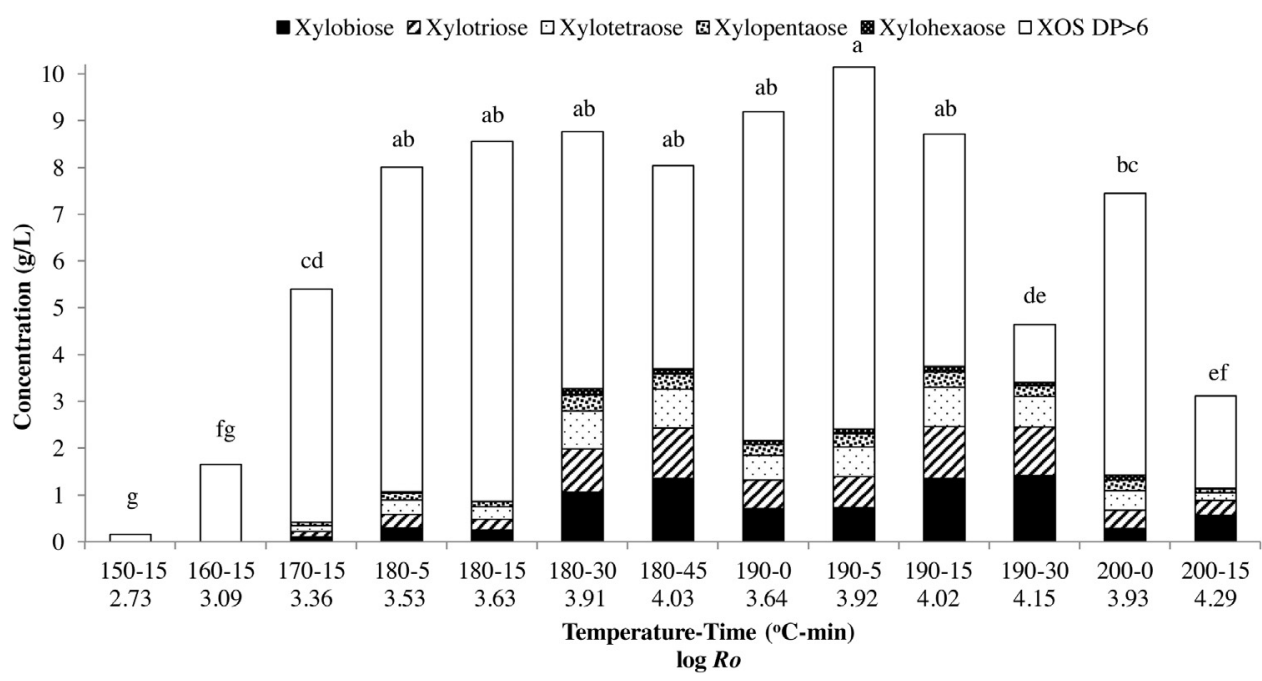

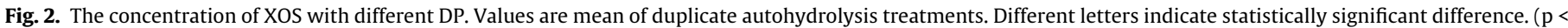
0.05, one-way ANOVA and Tukey test).

stocks or as a result of the methods applied for measurements. To our knowledge, there is no report in literature showing the composition of HPR.

\subsection{Autohydrolysis of hazelnut residues}

HS, $\mathrm{HH}$ and HPR were subjected to autohydrolysis at $190^{\circ} \mathrm{C}$ for $15 \mathrm{~min}$, corresponding to $\log R_{o}$ of 4.02 . The XOS concentrations in the liquors and the amounts of residual solids were measured to evaluate the efficiency of the treatments. For all three residues, more than one third of the starting material dissolved during the treatments (Table 2). Xylan was the main component removed from the lignocellulosic network, thus the process generated solids with increased cellulose and lignin content (Table 2). The cellulose content of treated HPR was $57.7 \%$, thus this biomass can be regarded as a potential source of glucose for bio-based chemical production via fermentative route. The concentration of XOS, which were the dominant carbohydrate, were measured as $8.2 \mathrm{~g} / \mathrm{L}, 3.3 \mathrm{~g} / \mathrm{L}$, and $7.3 \mathrm{~g} / \mathrm{L}$ in the liquors obtained from HS, HH and HPR, respectively. HS was concluded to be the most relevant hazelnut waste for XOS production, since its xylan content and the XOS concentration in its liquor after autohydrolysis were higher compared to the other hazelnut residues.

\subsubsection{Composition of processed solids of HS}

Autohydrolysis was applied to HS at a range of temperatures $\left(150-200^{\circ} \mathrm{C}\right)$ and holding times $(0-45 \mathrm{~min})$ in an effort to max- imize the XOS yield, while minimizing the by-product formation. The temperature and time combinations and the corresponding log $R_{o}$ values are shown in Table 2.

Solubilization of HS increased with $\log R_{0}$ up to $38.2 \%$ of the raw material (Table 2). Hemicellulosic carbohydrates are susceptible to hydrothermal treatment (Aachary \& Prapulla, 2011; Carvalheiro et al., 2008; Carvalheiro et al., 2009), so that more of the xylan and galactan solubilized as the reaction temperature and holding time increased. Consequently, the amount of xylan remained intact in the processed solids decreased with $\log R_{o}$ (Table 2), similar to the trends observed in the previous studies (Carvalheiro et al., 2009; Moniz et al., 2014; Moniz, Pereira, Quilhó, \& Carvalheiro, 2013). Arabinan was not detected in the solids after any treatments. The solubilization of hemicellulosic carbohydrates provided processed HS solids rich in cellulose and lignin (Table 2). Cellulose remained intact in the solid part after the treatments due to its tightly packed structure and resistance to autohydrolysis condition. Cellulose contents of the residual solids increased up to $30 \%$ from the initial value of $18.7 \%$ in the raw HS. Lignin was resistant to autohydrolysis as well, so that $85-90 \%$ of the initial amount remained in the solid after the treatment (Table 2). Following a biorefinery approach, the cellulose and lignin can be further fractionated and utilized as feedstocks for production of other bio-based chemicals and materials.

\subsubsection{Composition of HS autohydrolysis liquors}

Autohydrolysis liquors from lignocellulosic biomass contain; carbohydrates in monomeric and oligomeric (high and low molec- 

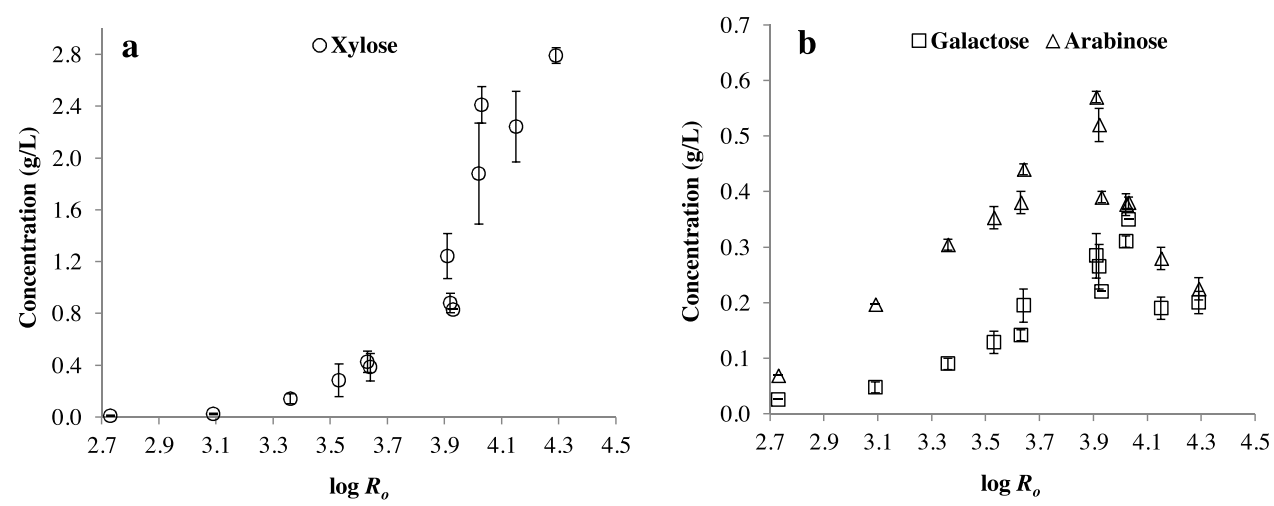

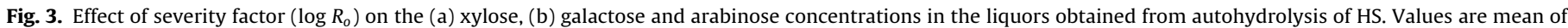
duplicate autohydrolysis treatments. Error bars represent standard deviation.

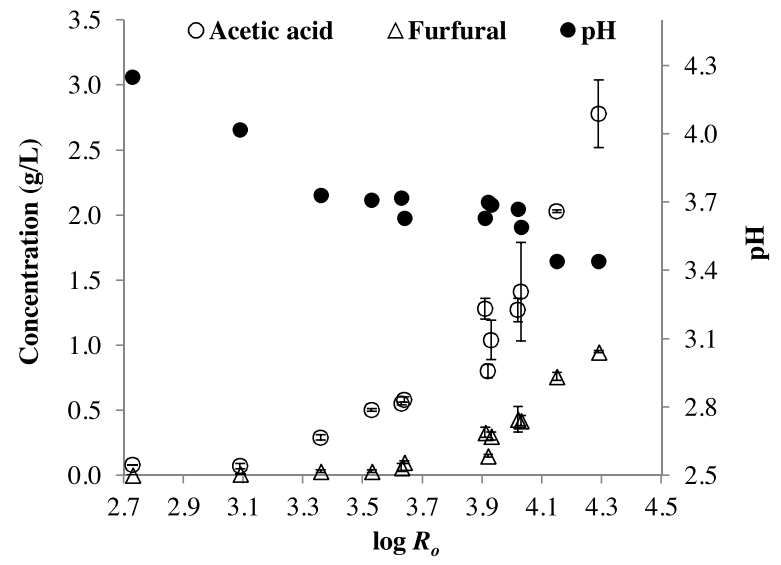

Fig. 4. Effect of severity factor $\left(\log R_{o}\right)$ on the liquor $\mathrm{pH}$ and the by-product concentrations. Values are mean of duplicate autohydrolysis treatments. Error bars represent standard deviation.

ular weight) forms; sugar degradation products such as acetic acid, formic acid, furfural and HMF; phenolic compounds or other extractives (Carvalheiro et al., 2004). Oligosaccharides, monosaccharides and carbohydrate degradation products in the liquors were measured after the autohydrolysis of HS (Figs. 1-4). XOS yield followed a parabolic trend with respect to $\log R_{0}$, peaking at $\log R_{o}$ values between 3.53 and 4.03 (Figs.1a and Fig. 2). The maximum yield was $62 \%$ of the initial xylan in the feedstock, which was obtained at log $R_{0}$ of $3.92\left(190^{\circ} \mathrm{C}-5 \mathrm{~min}\right)$, while $32.7 \%$ of the xylan did not dissolve and remained in the solid residue (Table 2). This yield value corresponded to liquor XOS concentration of $10.1 \mathrm{~g} / \mathrm{L}$. Below $\log R_{o}$ of 3.53 , the XOS yield was low due to the low solubility of the feedstock xylan during the treatments (Table 2). On the other hand, increasing the $\log R_{o}$ to 4.15 and 4.29 decreased the yield considerably, although xylan solubility was substantial (Table 2 and Fig. 1a). That was in parallel to increased monosaccharides, acetic acid and furfural formation at high $\log R_{o}$ values (Figs. 3 and 4 ). These results are in agreement to the proposed reaction mechanism of xylan degradation in autohydrolysis, i.e. XOS released from the feedstock xylan is degraded into xylose and further to sugar degradation products (Garrote \& Parajó, 2002; Gullón, Pereiro, Alonso, \& Parajó, 2009). In addition to XOS, small amounts of GaOS and glucooligosaccharides (GOS) were detected in the autohydrolysis liquor. The GaOS yield followed a trend similar to that of XOS. At medium severities, it reached approximately $47 \%$ of the galactan in the HS (Fig. 1b), corresponding to $0.7 \mathrm{~g} / \mathrm{L}$ GaOS in the liquor. The yield showed a sharp decrease afterwards, while at high $\log R_{o}$ values GaOS was not detected in the liquors. The GOS yield was relatively low (Fig. 1b) and between $0.11 \mathrm{~g} / \mathrm{L}$ and $0.22 \mathrm{~g} / \mathrm{L}$ GOS was detected in the liquors above $\log R_{0}$ of 3.09.

Similar to the raw HS xylan, the XOS from autohydrolysis were partly acetylated. Under high XOS yielding conditions, molar ratio of acetyl groups to xylose in the XOS structure was generally between 0.25 and 0.35 . XOS obtained from acetylated lignocellulosic biomass by autohydrolysis typically retains some of the acetyls of the raw material xylan (Garrote, Domínguez, \& Parajó, 1999; Ho et al., 2014; Nabarlatz et al., 2005; Xiao et al., 2013). Xylan extracted using alkali solutions for enzymatic XOS production, on the other hand, loses acetyl groups due to saponification of ester bonds (Nabarlatz et al., 2005). The degree of acetylation alters the solubility and the prebiotic activity of XOS. Kabel, Kortenoeven, Schols, \& Voragen (2002) showed that in vitro fermentation pattern of acetylated XOS by the fecal inocula was different than the non-substituted XOS and arabino-XOS in terms of utilization rate and short chain fatty acid and lactate formations.

Severity factor could explain the combined effect of temperature and time on the XOS yield (Fig. 1a). Not only XOS yields followed a certain trend along the $\log R_{o}$ values, but also different temperature and time couples that resulted in similar $\log R_{o}$ values yielded close XOS yields. Severity factor concept was used by some other groups for autohydrolysis and optimum $\log R_{o}$ values were generally close to those observed in this study. The highest XOS yields from corn straw was obtained at $\log R_{o}$ between 3.60 and 3.75 , while the yield decreased drastically above and below that range (Moniz et al., 2013). The same group also observed a similar trend for rice straw and obtained the maximum XOS yield at $\log R_{0}$ of 3.59 (Moniz et al., 2014). Carvalheiro et al. (2009) reported that XOS yield from wheat straw was maximum at $215^{\circ} \mathrm{C}\left(\log R_{o}=3.96\right)$. For XOS production from Miscanthus x giganteus, the optimum $\log R_{0}$ was around 3.5 , which was obtained at lower temperature $\left(160^{\circ} \mathrm{C}\right)$ but longer holding time (60 min) compared to the ones used in this study (Ligero, van der Kolk, de Vega, \& van Dam, 2011).

In addition to using severity factor for combined effect of temperature and holding time, it is possible to interpret their effects individually. The holding time influenced the XOS formation differently at $180^{\circ} \mathrm{C}$ and $190^{\circ} \mathrm{C}$ (Figs. $1 \mathrm{a}$ and Fig. 2). At $180^{\circ} \mathrm{C}$, the autohydrolysis yielded high amount of XOS irrespective of the holding time between 5 and $45 \mathrm{~min}\left(3.53 \leq \log R_{o} \leq 4.03\right)$. Similarly, XOS yields were high after autohydrolysis at $190^{\circ} \mathrm{C}$ for 0 and $15 \mathrm{~min}$. However, increasing the holding time to $30 \mathrm{~min}$ at this temperature, which increased $\log R_{0}$ to 4.15 , caused a pronounced decrease in the yield. Considering the treatments at different temperatures for 15 min of holding time, the XOS yields increased markedly with temperature between $150^{\circ} \mathrm{C}$ and $180^{\circ} \mathrm{C}$, whereas further increase to $190^{\circ} \mathrm{C}$ did not change the yield significantly. After autohydrolysis at $200^{\circ} \mathrm{C}$ the XOS were very low in the liquor, as discussed above. These trends were in accordance with the effect of treatment 
severity, i.e. above the optimum autohydrolysis treatment severity values, increase in either temperature or holding time had a negative effect on the XOS yield. These findings support the previous studies, which showed that the optimum holding time decreased with increasing temperature in XOS production by autohydrolysis of bamboo (Xiao et al., 2013), brewery's spent grain (Carvalheiro et al., 2004), olive tree pruning (Cara et al., 2012). Ligero et al. (2011) showed that the maximum XOS production from M. x giganteus was observed at $190^{\circ} \mathrm{C}$ when holding time was $5 \mathrm{~min}$ or $15 \mathrm{~min}$, whereas at longer holding times optimum temperature was lower.

XOS yield values obtained in this study were in accordance with yield values (\% of initial xylan) reported in literature for autohydrolysis of corncobs (59.4\%), almond shells (61.2\%), olive stones (53.5\%), wheat straw (41.2\%), barley straw (47.1\%) and rice husk (42.8\%) (Nabarlatz et al., 2007); oil palm empty fruit bunch fiber (63\%) (Ho et al., 2014); brewer's spent grain (61\%) (Carvalheiro et al., 2004); olive tree pruning residues (55\%) (Cara et al., 2012).

The DP of an oligosaccharide can have an effect on its fermentability in the gut. XOS with shorter chain lengths were reported to be consumed at a faster rate by the gut bacteria (Gullón et al., 2011; Moura et al., 2008). The XOS with DP between two to six (DP2-6) have been considered as low-DP XOS (Sun, Wen, Sun, \& Sun, 2015; Xiao et al., 2013). Low-DP XOS obtained from HS were composed mainly of xylobiose, xylotriose and xylotetraose (Fig. 2). At $150^{\circ} \mathrm{C}$ and $160^{\circ} \mathrm{Clow}$-DP XOS were not detected. At higher temperatures, excluding $200^{\circ} \mathrm{C}$, total low-DP XOS concentration increased almost linearly with treatment severity, while fraction of them in total XOS concentration increased exponentially (Fig. 2 and Fig. $\mathrm{S} 1$ ). At $200^{\circ} \mathrm{C}$, the total concentration and fractions of low-DP XOS were lower than expected by the corresponding trends. Xylobiose, xylotriose and xylotetraose concentrations increased linearly similar to total low-DP XOS, however, above $\log R_{0}$ of 4.03 , deviations from linearity were observed (Fig. 2 and Fig. S1).

The maximum total low-DP XOS concentration $(3.70-3.75 \mathrm{~g} / \mathrm{L})$ was obtained in autohydrolysis at $180^{\circ} \mathrm{C}$ for $45 \mathrm{~min}\left(\log R_{0}=4.03\right)$ and $190{ }^{\circ} \mathrm{C}$ for $15 \mathrm{~min}\left(\log R_{0}=4.02\right)$. Approximately $45 \%$ of the total XOS was low-DP under these conditions. The autohydrolysis at $190{ }^{\circ} \mathrm{C}$ for $30 \mathrm{~min}\left(\log R_{O}=4.15\right)$ yielded slightly less low-DP XOS $(3.41 \mathrm{~g} / \mathrm{l})$, but considerably lower amount of high DP XOS (DP >6). Consequently, low-DP XOS fraction was the largest (73\%) in this treatment, with xylobiose, xylotriose and xylotetraose fractions of $30 \%, 22 \%$ and $14 \%$, respectively. In all other treatments, major fraction was the high DP XOS, particularly when $\log R_{O}$ was below 3.64. Although the autohydrolysis treatments at $190^{\circ} \mathrm{C}$ for short holding times ( 0 and $5 \mathrm{~min}$ ) generated the highest total XOS, the low-DP XOS concentrations $(2.16 \mathrm{~g} / \mathrm{L}$ and $2.42 \mathrm{~g} / \mathrm{L}$, respectively) and their fractions (around 24\%) were comparably low.

In autohydrolysis at $180^{\circ} \mathrm{C}, 190^{\circ} \mathrm{C}$ and $200^{\circ} \mathrm{C}$, percentage of low-DP XOS increased with the holding time. At $180^{\circ} \mathrm{C}$, the fractions of low-DP XOS obtained with holding times of $5 \mathrm{~min}$ and 15 min were markedly less than the ones obtained with holding times of $30 \mathrm{~min}$ and $45 \mathrm{~min}$, although the total XOS concentrations were comparable in all four cases (Fig. 2). This effect was less pronounced at $190^{\circ} \mathrm{C}$. Carvalheiro et al. (2004) observed that at each temperature used for autohydrolysis of brewery's spent grain, DP of XOS mostly decreased with increasing holding time, while the highest amount of total XOS was obtained at moderate holding times. In autohydrolysis of mixed herbs and sunflower seed shells, percentages of low-DP XOS increased with reaction times, in parallel to decrease in high molecular weight XOS (Gullón et al., 2009). Increased low-DP XOS production at higher temperatures was also reported for sweet sorghum stems (Sun et al., 2015) and bamboo culm (Xiao et al., 2013).

Xylose concentration in the HS autohydrolysis liquor increased exponentially with $\log R_{o}$ (Fig. 3a). At medium treatment severity $\left(3.53 \leq \log R_{0} \leq 4.03\right)$, where XOS yields were similar (Fig. 1a), xylose was affected by the severity considerably. After autohydrolysis at $190^{\circ}$ for $5 \mathrm{~min}\left(\log R_{o}=3.92\right)$, under which conditions XOS concentration was the highest, xylose concentration was $0.88 \mathrm{~g} / \mathrm{L}$, corresponding to $4.1 \%$ of the initial xylan. This value is less than the xylose yields reported for rice straw (Moniz et al., 2014), wheat straw (Carvalheiro et al., 2009), corn straw (Moniz et al., 2013), oil palm fruit brunch fiber (Ho et al., 2014) and brewery's spent grain (Carvalheiro et al., 2004), while close to ones reported for sweet sorghum stems (Sun et al., 2015), bamboo culm (Xiao et al., 2013) and olive tree pruning (Cara et al., 2012). When the holding time was extended to $30 \mathrm{~min}$ at $190^{\circ} \mathrm{C}$ in order to maximize the low-DP XOS percentage, the xylose concentration increased to $2.24 \mathrm{~g} / \mathrm{L}(10 \%$ of the feedstock xylan). The concentrations of other monosaccharides, such as galactose and arabinose were relatively low (Fig. 3b). Unlike xylose, their concentrations decreased sharply after peaking at $\log R_{o}$ of 3.9-4.0. Galactose and arabinose may have been more susceptible to high treatment severity and their degradation may have started before xylose. On the other hand, decrease in xylose concentration due to thermal degradation may have been compensated by simultaneous degradation of XOS into xylose (Garrote \& Parajó, 2002; Gullón et al., 2009). Glucose was not detected at any of the treatments. Absence of glucose and very low concentrations of GOS indicate that hydrothermal treatment was not effective on cellulose (Ho et al., 2014; Parajó et al., 2004).

Under the autohydrolysis conditions, the ester bonds binding acetyl groups to the xylan are hydrolyzed and acetic acid accumulates in the reaction medium. Acetic acid has been known to act as a catalyst in the autohydrolysis medium and it is responsible for the hydrolysis of xylan into XOS. On the other hand, it is toxic to microorganisms, thus presence of it in a prebiotic product may diminish its activity. In HS autohydrolysis, acetic acid was the main by-product and its production increased exponentially with severity factor (Fig. 4). Under high XOS yielding conditions $(3.53 \leq \log$ $R_{o} \leq 4.03$ ) its concentration was between $0.5 \mathrm{~g} / \mathrm{L}$ and $1.5 \mathrm{~g} / \mathrm{L}$, while it reached to $2.78 \mathrm{~g} / \mathrm{L}$ at $\log R_{o}$ of 4.29 . These results match those reported for autohydrolysis of almond shells (Nabarlatz et al., 2005), brewery's spent grain (Carvalheiro et al., 2004), bamboo culm (Xiao et al., 2013) and sweet sorghum stems (Sun et al., 2015). The acid formation caused a decrease in $\mathrm{pH}$ of the liquors from the initial value of 4.9. Lower $\mathrm{pH}$ values were recorded as the $\log R_{o}$ increased (Fig. 4). The concentration of furfural, which is formed by dehydration of pentoses was relatively low and followed an exponential trend similar to xylose and acetic acid (Fig. 4). HMF and formic acid are the other by-products observed in hydrothermal treatments of lignocellulosics. In this study, HMF levels were very low $(<0.1 \mathrm{~g} / \mathrm{L})$, while formic acid was not detected in the HS autohydrolysis liquors.

\section{Conclusions}

This study has shown that autohydrolysis was effective for XOS production from HS. XOS yield was high under a wide range of moderate treatment severities, while maximum low-DP XOS percentage was obtained at higher severity values. These results suggest that autohydrolysis temperature and holding time should be carefully adjusted to obtain XOS with desired DP. The results also have shown that severity factor was successful in describing the trends of the oligomers, the monomers and the by-products formation in autohydrolysis treatments. Further research is needed to assess the prebiotic potential of the XOS produced from HS.

\section{Funding}

This research was supported by The Scientific and Technological Research Council of Turkey (Grant No: 2130126). 


\section{Acknowledgements}

The authors are grateful to Gürsoy Agricultural Products Food Industry and Trade Inc. (Ordu, Turkey) for providing the $\mathrm{HS}$ and $\mathrm{HH}$. The authors appreciate Biotechnology and Bioengineering Research and Application Center of Izmir Institute of Technology for providing laboratory facilities. The authors would like to thank Prof. Ahmet Yemenicioglu for stimulating discussions, Kevser Dogru for her help in laboratory studies, and Dr. Ceylan Buyukkileci for critical reading of the article.

\section{Appendix A. Supplementary data}

Supplementary data associated with this article can be found, in the online version, at http://dx.doi.org/10.1016/j.carbpol.2017.06. 109.

\section{References}

Çöpür, Y., Güler, C., Akgül, M., \& Taşçioğlu, C. (2007). Some chemical properties of hazelnut husk and its suitability for particleboard production. Building and Environment, 42(7), 2568-2572

Çöpür, Y., Tozluoglu, A., \& Özkan, M. (2013). Evaluating pretreatment techniques for converting hazelnut husks to bioethanol. Bioresource Technology, 129, $182-190$.

Çepelioğullar, Ö., \& Pütün, A. E. (2014). Products characterization study of a slow pyrolysis of biomass-plastic mixtures in a fixed-bed reactor. Journal of Analytical and Applied Pyrolysis, 110, 363-374.

Aachary, A. A., \& Prapulla, S. G. (2011). Xylooligosaccharides (XOS) as an emerging prebiotic: microbial synthesis, utilization, structural characterization, bioactive properties: and applications. Comprehensive Reviews in Food Science and Food Safety, 10, 2-16.

Akpinar, O., Gunay, K., Yilmaz, Y., Levent, O., \& Bostanci, S. (2010). Enzymatic processing and antioxidant activity of agricultural waste autohydrolysis liquors. BioResources, 5(2), 699-711.

Alkaya, E., Altay, T., Ata, A., Çakar, S. O., \& Durtas, P. (2010). Tarımsal atıklardan yüksek katma değerli biyoürün üretimi. In İleri teknoloji projeleri destek programi raporu [p. 35]

Aydinli, B., \& Caglar, A. (2012). The investigation of the effects of two different polymers and three catalysts on pyrolysis of hazelnut shell. Fuel Processing Technology, 93(1), 1-7.

Cara, C., Ruiz, E., Carvalheiro, F., Moura, P., Ballesteros, I., Castro, E., et al. (2012). Production: purification and characterisation of oligosaccharides from olive tree pruning autohydrolysis. Industrial Crops and Products, 40, 225-231.

Carvalheiro, F., Esteves, M. P., Parajó, J. C., Pereira, H., \& Gírio, F. M. (2004). Production of oligosaccharides by autohydrolysis of brewery's spent grain. Bioresource Technology, 91(1), 93-100.

Carvalheiro, F., Duarte, L. C., \& Gírio, F. M. (2008). Hemicellulose biorefineries: review on biomass pretreatments. Journal of Scientific and Industrial Research, 67(11), 849-864.

Carvalheiro, F., Silva-Fernandes, T., Duarte, L. C., \& Gírio, F. M. (2009). Wheat straw autohydrolysis: process optimization and products characterization. Applied Biochemistry and Biotechnology, 153(1-3), 84-93.

Carvalho, A. F. A., Neto, P. D. O., Da Silva, D. F., \& Pastore, G. M. (2013). Xylo-oligosaccharides from lignocellulosic materials: chemical structure, health benefits and production by chemical and enzymatic hydrolysis. Food Research International, 51(1), 75-85.

Demirbas, A. (2008). Oils from hazelnut shell and hazelnut kernel husk for biodiesel production Energy Sources, Part A: Recovery. Utilization and Environmental Effects, 30(20), 1870-1875.

Esposito, T., Sansone, F., Franceschelli, S., Del Gaudio, P., Picerno, P., Aquino, R. P., et al. (2017). Hazelnut (Corylus avellana L.) shells extract: phenolic composition, antioxidant effect and cytotoxic activity on human cancer cell lines. International Journal of Molecular Sciences, 18(2), 392.

FAOSTAT. (2017). Food and agriculture organization of the united nations statistics. [http://www.fao.org/faostat/en/\#data/QC (Accessed May 22, 2017).].

Finegold, S. M., Li, Z., Summanen, P. H., Downes, J., Thames, G., Corbett, K., et al. (2014). Xylooligosaccharide increases bifidobacteria but not lactobacilli in human gut microbiota. Food E' Function, 5(3), 436-445.
Garrote, G., \& Parajó, J. C. (2002). Non-isothermal autohydrolysis of Eucalyptus wood. Wood Science and Technology, 36(2), 111-123.

Garrote, G., Domínguez, H., \& Parajó, J. C. (1999). Mild autohydrolysis: an environmentally friendly technology for xylooligosaccharide production from wood. Journal of Chemical Technology and Biotechnology, 74(11), 1101-1109.

Gullón, P., Pereiro, G., Alonso, J. L., \& Parajó, J. C. (2009). Aqueous pretreatment of agricultural wastes: characterization of soluble reaction products. Bioresource Technology, 100(23), 5840-5845.

Gullón, P., Salazar, N., Muñoz, M. J. G., Gueimonde, M., Ruas-Madiedo, P., de los Reyes-Gavilán, C. G., et al. (2011). Assessment on the fermentability of xylooligosaccharides from rice husks. BioResources, 6(3), 3096-3114.

Guney, M. S. (2013). Utilization of hazelnut husk as biomass. Sustainable Energy Technologies and Assessments, 4, 72-77.

Ho, A. L., Carvalheiro, F., Duarte, L. C., Roseiro, L. B., Charalampopoulos, D., \& Rastall, R. A. (2014). Production and purification of xylooligosaccharides from oil palm empty fruit bunch fibre by a non-isothermal process. Bioresource Technology, $152,526-529$.

Kabel, M. A., Kortenoeven, L., Schols, H. A., \& Voragen, A. G. J. (2002). In Vitro fermentability of differently substituted xylo-oligosaccharides. Journal of Agricultural and Food Chemistry, 50(21), 6205-6210.

Ligero, P., van der Kolk, J. C., de Vega, A., \& van Dam, J. E. G. (2011). Production of xylo-oligosaccharides from Miscanthus $x$ giganteus by autohydrolysis. BioResources, 6(4), 4417-4429.

Melton, L. D., \& Smith, B. G. (2001). Determination of the uronic acid content of plant cell walls using a colorimetric assay. In Current Protocols in Food Analytical Chemistry E:E3:E3.3.

Moniz, P., Pereira, H., Quilhó, T., \& Carvalheiro, F. (2013). Characterisation and hydrothermal processing of corn straw towards the selective fractionation of hemicelluloses. Industrial Crops and Products, 50, 145-153.

Moniz, P., Pereira, H., Duarte, L. C., \& Carvalheiro, F. (2014). Hydrothermal production and gel filtration purification of xylo-oligosaccharides from rice straw. Industrial Crops and Products, 62, 460-465.

Moura, P., Cabanas, S., Lourenço, P., Gírio, F., Loureiro-Dias, M. C., \& Esteves, M. P. (2008). In vitro fermentation of selected xylo-oligosaccharides by piglet intestinal microbiota. LWT - Food Science and Technology, 41(10), 1952-1961.

Nabarlatz, D., Farriol, X., \& Montané, D. (2005). Autohydrolysis of almond shells for the production of xylo- oligosaccharides: product characteristics and reaction kinetics. Industrial and Engineering Chemistry Research, 44(20), 7746-7755.

Nabarlatz, D., Ebringerová, A., \& Montané, D. (2007). Autohydrolysis of agricultural by-products for the production of xylo-oligosaccharides. Carbohydrate Polymers, 69(1), 20-28.

Otieno, D. O., \& Ahring, B. K. (2012). A thermochemical pretreatment process to produce xylooligosaccharides (XOS): arabinooligosaccharides (AOS) and mannooligosaccharides (MOS) from lignocellulosic biomasses. Bioresource Technology, 112, 285-292.

Overend, R. P., Chornet, E., \& Gascoigne, J. A. (1987). Fractionation of lignocellulosics by steam-aqueous pretreatments. Philosophical Transactions of the Royal Society of London A: Mathematical, Physical and Engineering Sciences, 321(1561).

Parajó, J., Garrote, G., Cruz, J., \& Dominguez, H. (2004). Production of xylooligosaccharides by autohydrolysis of lignocellulosic materials. Trends in Food Science \& Technology, 15(3-4), 115-120.

Samanta, A. K., Jayapal, N., Jayaram, C., Roy, S., Kolte, A. P., Senani, S., et al. (2015). Xylooligosaccharides as prebiotics from agricultural by-products: production and applications. Bioactive Carbohydrates and Dietary Fibre, 5(1), 62-71.

Shahidi, F., Alasalvar, C., \& Liyana-Pathirana, C. M. (2007). Antioxidant phytochemicals in hazelnut kernel (Corylus avellana $\mathrm{L}$ ) and hazelnut byproducts. Journal of Agricultural and Food Chemistry, 55, 1212-1220.

Singh, R. D., Banerjee, J., \& Arora, A. (2015). Prebiotic potential of oligosaccharides: a focus on xylan derived oligosaccharides. Bioactive Carbohydrates and Dietary Fibre, 5(1), 19-30.

Sun, S., Wen, J., Sun, S., \& Sun, R.-C. (2015). Systematic evaluation of the degraded products evolved from the hydrothermal pretreatment of sweet sorghum stems. Biotechnology for Biofuels, 8(1), 37

Xiao, X., Bian, J., Peng, X. P., Xu, H., Xiao, B., \& Sun, R. C. (2013). Autohydrolysis of bamboo (Dendrocalamus giganteus Munro) culm for the production of xylo-oligosaccharides. Bioresource Technology, 138, 63-70.

Xu, Y., Sismour, E. N., Parry, J., Hanna, M. A., \& Li, H. (2012). Nutritional composition and antioxidant activity in hazelnut shells from US-grown cultivars. International Journal of Food Science and Technology, 47(5), 940-946. 